\title{
Noção de família(s) no campo da saúde brasileira: ensaio teórico-reflexivo
}

\author{
The family concept in the field of Brazilian health: a theoretical and reflective essay \\ Concepto de familia en el campo de la salud brasileña: ensayo teórico-reflexivo
}

\begin{abstract}
Lucas Lima Campos ${ }^{1}$ (C) Anna Karynne Melo ${ }^{1}$ (b)
\end{abstract}

1. Universidade de Fortaleza. Fortaleza, CE, Brasil.
Autor correspondente:

Lucas Lima Campos.

E-mail: limalucas230@gmail.com

Recebido em 14/06/2021.

Aprovado em 17/12/2021.

DOI:https://doi.org/10.1590/2177-9465-EAN-2021-0197

\section{RESUMO}

Objetivo: discutir o termo família no campo da saúde brasileira por meio: 1) do resgaste histórico do conceito e configuração da família no Brasil; 2) da recapitulação e problematização do termo na saúde brasileira; 3) da discussão na Política Nacional de Atenção Básica. Método: trata-se de um estudo teórico-reflexivo. Resultado: o texto foi dividido em: "Resgate histórico das transformações familiares no Brasil", "Primeira Unidade Básica de Saúde: a família" e "Política Nacional de Atenção Básica: de que família estamos falando?", que auxiliaram na argumentação sobre a problemática da (não)definição do termo família. Em meio a preocupação sobre alocar o cuidado voltado para a família, torna-se necessário repensar esse termo polissêmico, propondo a desnaturalização de definições cristalizadas que podem emergir na práxis dos profissionais, o que pode produzir atuações baseadas em (pré-)conceitos e negligências a famílias não hegemônicas. Considerações finais e implicações para a prática: é necessário discutir sobre qual concepção de família é considerada no campo da saúde e suas repercussões, principalmente na Atenção Primária à Saúde e em políticas de saúde, como na Política Nacional de Atenção Básica, para minimizar possíveis dificuldades que possam surgir no fazer dos profissionais ao se deparar com a pluralidade das realidades familiares.

Palavras-chave: Atenção Primária à Saúde; Família; Política de Saúde; Saúde da Família; Saúde.

\begin{abstract}
Objective: to discuss the term family in the field of Brazilian health through: 1) the historical review of the concept and family arrangement in Brazil;2) the recapitulation and problematization of the term in Brazilian health; 3) the discussion in the Brazilian National Primary Care Policy. Method: this is a theoretical-reflective study. Results: the text was divided into: "Historical rescue of family transformations in Brazil", "First Basic Health Unit: the family" and "Brazilian National Primary Care Policy: which family are we talking about?", which helped in the argument about the problem of (non)definition of family. Amidst the concern about allocating family-oriented care, it becomes necessary to rethink this polysemic term, proposing the denaturalization of crystallized definitions that can emerge in professionals' work, which can produce actions based on (pre-)concepts and negligence to non-hegemonic families. Final considerations and implications for practice: it is necessary to discuss which conception of family is considered in the field of health and its repercussions, especially in Primary Health Care and in health policies, as in the Brazilian National Primary Care Policy, to minimize possible difficulties that may arise in professionals' actions when faced with the plurality of family realities.
\end{abstract}

Keywords: Primary Health Care; Family; Health Policy; Family Health; Health.

\section{RESUMEN}

Objetivo: discutir el término familia en el campo de la salud brasileña a través de: 1) la revisión histórica del concepto y configuración de la familia en Brasil; 2) por la recapitulación y problematización del término en la salud brasileña; 3) para la discusión en la Política Nacional de Atención Primaria. Método: es un estudio teórico-reflexivo. Resultado: el texto se dividió en: "Rescate histórico de las transformaciones familiares en Brasil", "Primera unidad básica de salud: la familia" y "Política Nacional de Atención Primaria: ¿de qué familia estamos hablando?”, Que ayudó en la argumentación sobre el problema de la (no) definición del término familia. En medio de la preocupación por la asignación de cuidados orientados a la familia, se hace necesario repensar este término polisémico, proponer la desnaturalización de definiciones cristalizadas que pueden surgir en la praxis de los profesionales, que pueden producir acciones basadas en (pre) conceptos y negligencia de familias no hegemónicas Consideraciones finales e implicaciones para la práctica: es necesario discutir qué concepción de familia se considera en el campo de la salud y sus repercusiones, principalmente en la atención primaria de salud y en las políticas de salud, como la Política Nacional de Atención Primaria, para minimizar las posibles dificultades que puedan surgir en la actuación de los profesionales ante la pluralidad de realidades familiares.

Palabras clave: Atención Primaria de Salud; Familia; Política de Salud; Salud de la Familia; Salud. 


\section{INTRODUÇÃO}

O termo família, originário do latim famulus, cujo significado remete aos termos criado, servidor e escravo doméstico, apresenta diferentes usos no cotidiano, englobando diversos significados e interpretações. ${ }^{1-2}$ Esse aspecto polimorfo advém das variadas percepções culturais, sociais, políticas, ideológicas e das diversas teorias presentes nos campos de estudos voltados para família, o que torna difícil a compreensão do termo em uma única definição. ${ }^{1}$

A dificuldade em universalizar o termo família pode ser vista em uma revisão da literatura desenvolvido em 2003, cujo um dos objetivos foi identificar as teorias mais utilizadas em estudos sobre família, sendo encontradas dezesseis teorias que produziam concepções específicas sobre o termo. ${ }^{3}$ Quase dez anos depois, outro estudo foi realizado pelos mesmos autores, que identificaram um aumento no quantitativo dos achados de 2003, sendo agora 51 teorias que versam sobre a concepção de família. ${ }^{4}$ Esse aumento acompanha uma "tendência" que o termo possui de diversas modificações em sua definição, muitas vezes amparadas por mudanças sociais e culturais. Devido ao termo família se organizar a partir de uma relação intersubjetiva do mundo, é alicerçado pelo intercâmbio simbólico entre gêneros e gerações, pela mediação entre cultura/natureza e esfera privada/pública, sendo um produto atrelado à cultura, tempo e contextos determinados. ${ }^{5}$

$\mathrm{Na}$ trajetória do termo família, diferentes interpretações emergem advindas de eventos históricos que modificam os parâmetros sociais hegemônicos e que possibilitam a (re) construção de paradigmas. Entre esses eventos, as conquistas dos movimentos feministas no reconhecimento dos múltiplos papéis das mulheres, a possibilidade do divórcio e de guarda compartilhada, e o reconhecimento das famílias homoafetivas foram alguns dos acontecimentos que influenciaram na construção da família. ${ }^{6}$ Mesmo com a ausência de uma definição consensual, o termo família é utilizado indiscriminadamente em diversos contextos com diferentes propósitos, como no âmbito da saúde brasileira, em que o termo se torna mote para o desenvolvimento de políticas públicas. ${ }^{7}$

No Brasil, a relação entre saúde e família tem se demonstrando longínqua. Seja nas intervenções pautadas no processo de aristocratizar a população aos padrões burgueses, como no período colonial, do desenvolvimento de campos especializados como a medicina da família, ou na elaboração de programas em saúde que utilizam a família como ponto-chave, a relação família/saúde permanece constante. ${ }^{8}$ Principalmente após a Reforma Sanitária, que proporcionou novas discussões sobre o paradigma saúde/doença, assumindo a família como conceito basal para diferentes estratégias de cuidado em saúde que auxilia no repensar do processo saúde/doença. ${ }^{7}$

Nesse contexto, sendo um termo fundamental a lógica de funcionamento adotada no campo da saúde, um questionamento básico emerge ao discutir essa temática: afinal, de qual família estamos falando no campo da saúde brasileira? Na tentativa de contribuir para a reflexão dessa temática, o objetivo deste artigo é discutir o termo família na saúde brasileira, por meio de três aspectos: 1) resgaste histórico do conceito e configuração da família no Brasil; 2) recapitulação e problematização do termo na saúde brasileira; 3) discussão na Política Nacional de Atenção Básica (PNAB), devido à sua importância na estruturação da estratégia da saúde da família. Para organização da discussão, o texto foi organizado em três partes, com as temáticas: Resgate histórico das transformações familiares no Brasil; Primeira Unidade Básica de Saúde: a família; e Política Nacional de Atenção Básica: de que familia estamos falando?

\section{MÉTODO}

Trata-se de um estudo teórico-reflexivo, pautado nas discussões realizadas por Archanjo $^{8}$, $\operatorname{Trad}^{9}$ e Mioto $^{10}$ sobre o papel da família na saúde pública brasileira e no posicionamento dos autores acerca do (re)pensar a noção de família.

\section{RESULTADOS E DISCUSSÃO}

\section{Resgate histórico das transformações familiares no Brasil}

No decorrer da história brasileira, a família foi a instituição que, desde o período colonial, representou os padrões e normas de conduta estabelecidos pela sociedade. Da família voltada ao patriarcado, que exacerbava o poder e figura paterna, a que foi foco de práticas higienistas, com o intuito do desenvolvimento de comportamentos considerados adequados pela burguesia e aquela em que o amor romântico modificou as relações matrimoniais, a família assumiu diferentes identidades e características ao longo dos anos. Nessa transformação, três grandes recortes históricos ajudam a compreender as trajetórias das mudanças que ocorrem na família: o período de maior vigência da família no modelo tradicional (até o final do século XVIII); o modelo moderno (entre o século XIX e meados do século $X X$ ); e o contemporâneo ou pós-moderno (vigente da década de 60 até o período atual). ${ }^{8}$

\section{A família no modelo tradicional: até o final do século $X V I I I$}

O modelo familiar tradicional foi marcado na história do Brasil pelos aspectos sociais vigentes na sociedade colonial, demarcado pelo escravismo e patriarcalismo. ${ }^{11} \mathrm{~A}$ economia brasileira se encontrava presente na Região Nordeste do país, onde vastas plantações de cana de açúcar eram o foco da produção nos engenhos localizados nas regiões rurais, caracterizando os latifúndios em que residiam as famílias de elite em grandes casarões, cercadas de escravos e dependentes. ${ }^{1,12}$ A compreensão sobre família não se restringia apenas à lógica consanguínea, pois os membros que participavam da família tradicional englobavam aqueles que dividiam parentesco de sangue, como esposa e filhos, e também indivíduos que estabeleciam relações fundadas em diversos outros elementos, como o religioso e sentimental compadres e agregados. Todos deviam obediência para a figura 
do patriarca, pois todos estavam sob a proteção e ordens dele, independente da relação estabelecida. ${ }^{8}$

As atividades que cada membro da família exercia estavam bem amparadas por costumes e tradições apoiados por leis que legitimavam o modelo tradicional dentro e fora do âmbito doméstico e que priorizavam o poder pátrio, sendo este a pedra angular do modelo tradicional. ${ }^{11}$ Os outros membros da família apenas obedeciam e temiam as punições advindas do patriarca e detinham níveis sociais diferentes - as esposas ficavam reclusas em casa e os filhos ocupavam apenas um papel instrumental na família - e os dois detinham o mesmo nível social dos escravos. Os casamentos eram compreendidos como negócios entre famílias, não havia local para sentimentos românticos entre os cônjuges, e relações endogâmicas eram comuns, pois tinham a função de impedir a dispersão dos bens/poder do patriarca. Os membros da família não possuíam cômodos próprios em suas residências e eram superpovoados, com empregados, parentes e agregados, o que propiciava a ausência de intimidade e privacidade entre os familiares. ${ }^{11-13}$

A figura do patriarca era sustentada por uma elite senhorial que baseava seu poder na posse de terras e escravos, que prezava pela conservação da estrutura social, sendo o reconhecimento do poder patriarcal necessário para essa manutenção. O papel familiar estruturado nessa lógica tinha grande influência no domínio político, pois as ações e participação política dependiam das relações estabelecidas com a figura do patriarca, que procurava representantes que defendessem seus interesses no espaço formal de poder, legitimando a dominação do patriarcado. ${ }^{1,11}$

Diferentes obras abordaram esse contexto familiar, como Casa Grande e Senzala de Gilberto Freyre (1900-1987), e, por algum tempo, foi considerado o único modelo hegemônico de família, entretanto, mesmo na vigência do modelo tradicional, outras formas de família existiam com outros modelos de organização. Famílias com poucos membros, viúvos(as), pais solteiros, com escravos ou índias ${ }^{a}$, concubinato (relações estáveis sem autorização da Igreja) e ilegítimos (filho fora do casamento civil e religioso) são alguns exemplos de outros tipos de famílias que ocorriam em conjunto ao modelo tradicional, mas que ocorriam em maior demasia nas classes menos abastardas (na exceção, o concubinato), devido às características presentes na época, como o alto fluxo migratório para exploração do território nacional, a burocracia e os agravos financeiros que envolviam a realização do casamento (civil ou religioso). ${ }^{16}$

Um adendo importante a fazer é que o modelo patriarcal, enfatizado até agora, encontra-se não apenas na história colonial, mas na moderna e contemporânea, porém tende-se a modificar esse modelo com o passar histórico, modificando algumas características. Esse modelo perde um pouco a força no final do século XVIII, quando a Corte portuguesa desembarca no Brasil, trazendo com ela mudanças que afetariam a estrutura da sociedade e o entendimento social da família.

\section{A família moderna: do século XIX até os meados do século XX}

A chegada da Corte portuguesa ao Brasil marca diversas mudanças nas estruturas sociais, culturais, políticas e econômicas. Anteriormente, o poder da província, mesmo ainda submetida à Portugal, encontrava-se em embate constante com a elite senhorial e suas exigências, o que causava incômodo para a Corte portuguesa, mas era um inconveniente suportado pela metrópole. Entretanto, com a chegada da Coroa portuguesa ao Brasil, o poder da província teria que ser voltado para a Corte e não para a elite senhorial. Para isso, novas regras foram implementadas para que a elite brasileira absorvesse os ideais de vida europeus. Nesse ponto, não bastava mais a elite brasileira possuir posses ou qualquer ligação com tradições locais, o que importava era a possibilidade de "aristocratizar-se". 8,12

O processo de "aristocratizar-se" objetivava o enquadramento dos colonos aos ideais burgueses, sendo marcado pelo conhecimento médico que proporcionou o embasamento científico ao Estado para desempenhar práticas que visavam às transformações sociais desejadas pela classe dominante.

A introjeção dos padrões desejados de práticas e comportamentos tinha por objetivo constituir um modelo de organização familiar mais adequado ao ideal liberalportuguês, tendo como consequência (ou causa) a desestruturação da família patriarcal e a promoção da centralização do poder do Estado. ${ }^{8: 29}$

O poder do patriarca precisava ser ressignificado para ocorrer o enfraquecimento do poder familiar e, por consequente, o poder da elite senhorial. Por meio do poder médico, relações familiares do modelo tradicional foram ressignificadas, a consanguinidade entre os membros de uma família foi colocada como fator primordial para a definição familiar, afastando os parentescos compreendidos pela religião ou laços sentimentais. Os papéis dos membros familiares foram bem definidos e diferenciados para o "bom funcionamento familiar", atribuindo para cada indivíduo uma responsabilidade - a mulher era responsável pelo cuidado doméstico e criação dos filhos; o marido ficava com o papel de provedor; os filhos, antes apenas pequenos adultos que cresceriam para ajudar a família, tornam-se a figura central da família. 8,11

A definição dos papéis familiares e a higienização dos comportamentos produziram mudanças marcantes nas estruturas sociais brasileiras, ao retirar certos privilégios voltados ao patriarca e ao estabelecer regras a serem seguidas. ${ }^{11,17} \mathrm{~A}$ higienização da família acentuou o risco dos vícios sociais, doenças físicas e violências morais, exaltando a influência materna na educação dos filhos. A família se torna mais restritiva e menor. As residências, anteriormente grandes e sem compartimentos particulares, começam a ser estruturadas pensando em cômodos específicos para cada membro e suas funções familiares. A individualização da família começa a ocorrer visando aos papéis sociais familiares 
estabelecidos e ao enfraquecimento do modelo anteriormente definido. ${ }^{8}$

A relação entre os indivíduos começa a ser compreendida pela reciprocidade de sentimentos e desejos carnais, sendo agora entendida como parte importante para o matrimônio e procriação. A constituição familiar deixa de ser apenas um negócio para o patriarca e passa agora para a esfera do desejo e sentimento dos cônjuges, surgindo, assim, o ideal de família nuclear embasado pelo amor, proteção e cuidado com a infância. ${ }^{8,17}$

Entretanto, o novo modelo familiar se estabelece apenas para a estruturação da burguesia, o que excluía grande parte da população brasileira que não possuía a mesma realidade econômica da elite para seguir as regras higienistas estabelecidas (como ter a própria casa com compartimentos individuais, as mulheres se voltarem apenas para o cuidado doméstico e criação dos filhos), o que se tornaria um problema em meados do século $X X$, quando o Brasil inicia o seu processo de industrialização e as classes menos abastadas encontram dificuldades em seguir o "progresso". Diversos mecanismos foram desenvolvidos na tentativa de suprir as dificuldades estabelecidas pelas práticas higienistas familiares, como o desenvolvimento de vilas operárias nas fábricas, em que os operários seguiam as regras estipuladas e conseguiam (adaptavelmente) ser "higienizados". ${ }^{8}$

\section{A família contemporânea ou pós-moderna: década de 60 até o período atual}

A partir de 1960, a compreensão sobre o que é família encontra novas modificações advindas das transformações sociais e culturais constantes, como a inserção da mulher no mercado de trabalho; o fortalecimento do sistema capitalista e a dinamização da economia; a difusão do ideário anarquista e os movimentos de contracultura que se opuseram à europeização dos costumes; a intensificação dos movimentos feministas; as mudanças juristas sobre o matrimônio, que influenciaram no desenvolvimento e modificação do que é compreendido como família no Brasil e no mundo. ${ }^{8}$ As modificações ocorrem, principalmente, na forma de organização familiar, em que começa a seguir moldes mais igualitários, e homens e mulheres dividem uma posição de identidade idiossincrática baseada nas diferenças individuais de cada membro, tornando-se mais nuclear e privatizada, devido à fragmentação de sentidos e à crise das figuras consideradas de autoridade. ${ }^{17}$

Essas mudanças propiciam a diversidade de configurações e relações entre membros de uma mesma família, desenvolvendo arranjos diferenciados que propõem variadas formas de famílias e renovam conceitos preestabelecidos, redefinindo os papéis de cada membro do grupo familiar.8,18 Nessas novas formas, encontram-se famílias de pais separados (em que os filhos não convivem com a figura materna ou paterna), constituídas por casais homossexuais com filhos (adotados ou gerados em laboratório), formadas por irmãos e sobrinhos, avós, netos, entre outros parentescos, famílias monoparentais (constituídas apenas de filhos e uma figura parental), famílias formadas por uniões de pessoas com filhos de outros casamentos e mais formas de famílias a serem definidas. Nesse contexto, a definição contemporânea de família acaba sendo alicerçada nos aspectos afetivos de proximidades com entes queridos e na opinião dos membros sobre o que os fazem ser parte de uma família. ${ }^{18}$ Outras configurações emergem devido à solidariedade relativa às condições socioeconômicas (principalmente as camadas mais pobres e que sofrem discriminação), em que membros familiares precisam permanecer em convívio no mesmo ambiente, visando sobreviver às adversidades econômicas e sociais existentes, acarretando a ampliação do número de membros ativos da família. ${ }^{19}$

\section{Primeira Unidade Básica de Saúde: a família}

Entre os diferentes saberes que agem sobre o contexto familiar, os conhecimentos advindos de áreas correlacionadas ao campo da saúde estiveram continuamente presentes no âmbito familiar, em virtude de: 1) a família ser um dos primeiros contextos que os indivíduos são inseridos; e 2) por ser um dos primeiros âmbitos de cuidado informal. ${ }^{5}$ Nesse cuidado provido, esperase que haja o acolhimento e o suprimento das necessidades físicas e psicológicas dos membros familiares e, concomitante a esse processo, que ocorra a projeção dos valores culturais, éticos, morais e humanitários, que perpetuam comportamentos sociais importantes para a vida em sociedade..$^{2,5}$

Énessa compreensão sobre as responsabilidades que a família "deve" exercer (a palavra deve se encontra aspada, uma vez que as atividades atribuídas à família passam por problemáticas de definição e disponibilidade para serem exercidas), que está assume local central em diversas políticas de saúde. Principalmente após a Reforma Sanitária, que proporcionou novas discussões sobre o paradigma saúde/doença, oportunizando debates voltados à atenção comunitária e familiar, remodelando os serviços de saúde que, até então, seguiam a lógica do paradigma centrado na doença voltada para aspectos de caráter individualizante com intervenções biológicas predominantes. Para o modelo preconizado pela reforma, torna-se insuficiente para compreensão do processo saúde e doença em sua totalidade..$^{2,19}$

Tendo em vista esse contexto, a família é eleita como mote central de políticas públicas a partir da Reforma Sanitária, porque, ao compreender e intervir na família, os determinantes sociais, políticos e econômicos, como os aspectos laborais, de território e biológicos, emergem como características importantes que influenciam no processo saúde e doença, evitando a redução dos indivíduos em partes anatômicas e na exclusão do seu contexto social. ${ }^{2,10} \mathrm{~A}$ família:

[...] não pode ser desconsiderada quando se trata de políticas públicas [...] caracteriza-se como um espaço complexo, que se constrói e se reconstrói histórica e cotidianamente através das relações e negociações que estabelece entre seus membros, entre seus membros e outras esferas da sociedade e entre ela e outras esferas da sociedade, como Estado, trabalho e mercado. ${ }^{10: 54}$ 
Sob essa premissa, em 1994, o Programa Saúde da Família (PSF) acaba sendo constituído como método de estruturação e fortalecimento dos ideais preconizados pelo novo modelo de atenção à saúde, possibilitando ações de promoção à saúde do indivíduo, da família e da comunidade, de forma integral e contínua, atendendo os usuários na unidade de saúde local, no domicílio e nos espaços existentes disponíveis nos territórios. ${ }^{2}$ Mesmo com o passar dos anos, a família continua como foco das políticas públicas, e o PSF acaba sendo estruturado e organizado passando a ser nomeado como Estratégia Saúde da Família (ESF). Em 28 de março de 2006, por meio da Portaria no 648 , o MS publicou a PNAB, tornando-se um marco histórico para a consolidação nacional da ESF, visando à reorganização da Atenção Primária à Saúde (APS). Em 2008, ocorre a implementação dos Núcleo Ampliado de Saúde da Família (NASF), visando ampliar a resolutividade das ações e serviços de APS. ${ }^{20} \mathrm{Em} 2017$, com a revisão da PNAB por meio da Portaria $n^{\circ}$ 2.436, o NASF tem a nomenclatura alterada para Núcleo Ampliado de Saúde da Família e Atenção Básica (NASF-AB).

Essa continuidade da relação família e saúde se sustenta, devido a diferentes aspectos que permeiam tanto necessidades sociais de saúde como também a fragilidade do Estado na provisão de elementos necessários para o bem-estar social. Existem três características que alocam a família na referência de políticas públicas, ${ }^{10}$ são elas: 1) os indivíduos são avaliados mais pelas condições de vida que a família possui do que pelo status individual que possuem na sociedade;2) quando a família consegue exercer o cuidado informal para os seus membros, acaba por diminuir uma possível demanda que o Estado possa ter em serviços de assistência; 3 ) "[...] ao se considerar a saúde como um bem especial, parte constituinte direta do bem-estar de cada pessoa, e ao se reconhecer o protagonismo dos determinantes sociais nas condições de saúde da população, torna-se impensável descartar a família como referência importante das políticas públicas". 10:54-55

A possível lacuna de assistência provida pelo Estado no campo da saúde, para a população em geral, e a utilização da família como forma de suprimir essa falta se apresentam perante o desvio de políticas públicas de caráter universal, em detrimento de políticas voltadas para segmentos populacionais específicos, ocasionando o fortalecimento do mercado como provedor de bem-estar e de organizações civis. Nesse contexto, a família utiliza outros artifícios não provenientes do Estado e que estão disponíveis por outras instâncias para sustentar o cuidado que provém para os membros familiares, como no âmbito da saúde, em que acontece a participação recorrente das iniciativas privadas para preencher as lacunas que ocorrem no prover do Estado. ${ }^{10}$

No retraimento do Estado, as famílias adotam soluções que estão alicerçadas na autonomia dos grupos, seguindo a lógica neoliberal individualizante, mas que encontram dificuldades em sua resolutividade devido às inequidades sociais presentes no cotidiano (alta taxa de desemprego, alto custo de alimentação e moradia, etc.), o que gera o esgotamento das famílias para atender às exigências de proteção social e retrocessos em termos de cidadania social. ${ }^{10,21}$ Essa vulnerabilidade influencia na redução dos integrantes pertencentes ao grupo familiar e no desenvolvimento de processos voltados para o empobrecimento e desterritorialização das famílias. ${ }^{10} \mathrm{Na}$ tentativa de manter sua característica protecionista e promoção de bem-estar, o grupo familiar utiliza diversos artifícios, como os (re)arranjos de papeis familiares, em que ocorre a mudança de funções no sistema familiar, ou a solidariedade entre os integrantes. ${ }^{21-22}$

Outro tópico importante a ser ressaltado nas possíveis problemáticas na utilização da família como ponto-chave de políticas públicas é a caracterização do termo família. Afinal, o termo possui diferentes definições que caracterizam uma vasta possibilidade de configurações familiares que podem sinalizar para diferentes formas de cuidado e que possibilitam a discussão sobre qual família está sendo abordada nos textos descritivos das políticas públicas em saúde. Partindo dessa temática, será analisado e discutido a seguir como o termo família é desenvolvido nas Portarias no 2.436, no 2.436 e no 648 referentes à PNAB, devido à importância dessa política nas ações do SUS.

\section{Política Nacional de Atenção Básica: de que família estamos falando?}

Como demonstrado anteriormente, a Portaria no -648 consolidou a ESF, reorganizando a APS em território nacional por meio da PNAB. A publicação iniciou discussões sobre a organicidade institucional voltada para a rede de atenção, provendo recomendações para os serviços de saúde, norteando processos de trabalho, funções das categorias profissionais, financiamento do sistema, entre outras recomendações, incorporando e difundindo os atributos da atenção primaria em saúde..$^{23} \mathrm{Em} 2011$, a Portaria foi revogada pela publicação de no-2.488 no dia 21 de outubro, estabelecendo a revisão de diretrizes e normas que organizam a APS na ESF e o Programa de Agentes Comunitários de Saúde. Nessa nova mudança na PNAB, reafirmam-se os pontos abordados na edição anterior, mas flexibilizando a carga horária da categoria médica para suprir a falta dos profissionais nas equipes. ${ }^{23}$

Posteriormente, na publicação da Portaria no 2.436, promulgada no dia 21 de setembro de 2017, é realizada a revisão de diretrizes para a organização da APS no âmbito do SUS, trazendo modificações na relativização da cobertura universal, na definição de padrões distintos de serviços, na recomposição das equipes e na reorganização do processo de trabalho. ${ }^{24} \mathrm{~A}$ leitura dessas Portarias se demonstra necessária, devido que: 1) apresentam as transformações nos aspectos teóricos e práticos da ESF ao longo das revisões realizadas;2) são registros históricos e oficiais das mudanças das diretrizes utilizadas; 3) estão presentes em diversas matérias de ensino que possuem como objetivo esclarecer as diretrizes da ESF.

Na procura da definição que embasa a noção de família pela ESF, foram analisados os documentos na íntegra disponíveis na internet, buscando possíveis definições para o termo família e identificando prováveis características que estão sendo englobadas ao termo. Os resultados encontrados são que as portarias apresentam, em conjunto a repetição do termo família, 
359 vezes (Portaria no 648 - 106, № 2.488 - 161, ํㅡ 2.436 - 92), associado à palavra estratégia ou utilizado de maneira a classificar o público-alvo, mas não abordam a definição que embasa as diretrizes da PNAB, o que difere do cuidado descritivo e conceitual que a política possui sobre outros elementos que a compõem.

As versões do documento descrevem de forma objetiva $e$ clara as diversas responsabilidades que devem ser exercidas pelas equipes da APS, abarcando diversas atividades financeiras, implantação e educação permanente, que embasam as responsabilidades da gestão, até as atividades que devem ser realizadas pelos profissionais atuantes nas Unidades Básicas de Saúde. O mesmo detalhamento de informações aparece na descrição de conceitos básicos para o entendimento da PNAB, como a definição de APS e NASF-AB, em que são explanadas as funções, as ações necessárias e as justificativas para essas propostas, especificamente a definição e os fundamentos pertencentes à APS que, ao longo das edições, acaba sendo mais detalhada e composta por mais características. Entretanto, a mesma acurácia de descrição não ocorre na definição sobre família.

Na recorrência do termo família, ao longo das portarias referentes à PNAB, existe uma lacuna no que concerne à perspectiva utilizada para sustentar a ideia da família como um mote de política pública e qual a concepção do termo está sendo adotada. Ademais, também não ocorre a sinalização de algum documento oficial que possa ser consultado sobre os aspectos citados alhures, deixando a cargo do leitor a interpretação que the convém. Nesse aspecto, surge a pluralidade de compreensões referentes à família oriundas da ontogenia particular de cada indivíduo, que podem estar de acordo (ou não) com os elementos e diretrizes presentes na política pública, no caso, a PNAB.

$\mathrm{Na}$ falta da definição formal (ou orientação) e a possibilidade de compreensão subjetiva sobre o termo família, emerge um espaço sem restrições de conceituações, especialmente para os profissionais de saúde, que podem alocar interpretações individuais sobre o entendimento de família em sua práxis. Sobretudo, concepções que são recorrentes no campo da saúde, como a compreensão de família a partir do ciclo de vidas, ou como uma unidade doméstica em que pessoas residem e são divididas por características biológicas, ${ }^{11,25}$ são concepções orientadas em aspectos específicos que restringem a pluralidade familiar. Esse cenário pode ser visualizado em um estudo realizado com 24 profissionais atuantes na ESF, cujo o objetivo foi tentar apreender o significado de família. ${ }^{26}$ Foi constatado que os profissionais participantes da pesquisa apresentaram dificuldades em conceituar o termo família, apresentando descrições vagas e que excluíam configurações não hegemônicas, pautadas apenas em aspectos biológicos que propiciava uma atuação curativista focada na doença, não promovendo ações reais de promoção à saúde e acarretando prejuízo à saúde de uma parcela da população. ${ }^{26}$

A desassistência de configurações não hegemônicas de famílias, seja na omissão de suas necessidades ou reconhecimento de direitos básicos, ou mesmo na desqualificação da configuração familiar, não se alinha com os ideais propostos na Reforma Sanitária, na qual compreende a amplitude do processo saúde e doença para além de características específicas, o que torna necessário a problematização constante das relações familiares para:

[...] uma atenção integral da saúde, com foco na família, tanto no que se refere às formas próprias de cuidado à saúde e às doenças utilizadas pelas famílias, como também no que diz respeito às implicações das relações familiares no próprio processo de adoecer, dentro do que pretende ser uma compreensão ampliada do chamado processo saúde-doença, que leve em conta as dimensões biológicas, psicológicas e sociais destes processos. ${ }^{25: 94}$

Essa problematização constante também precisa ocorrer, devido aos processos históricos ${ }^{b}$ e cotidianos que estão imbricados e que fazem parte da constituição familiar, como casamento, gravidez, nascimento, falecimento, orfandade, emancipação, dentre outros, que afetam os elementos da configuração familiar e atribuem (ou modificam) diferentes funções aos membros do grupo. Como demonstrando alhures, os (re)arranjos familiares são multideterminados, a família se (re) configura a partir das possibilidades presentes em seu contexto ambiental e histórico, quebrando perspectivas cristalizadas de relações puramente sanguíneas e/ou genéticas, organizando-se também em relações afetivas e de sobrevivência (e.g., famílias monoparentais, granparentais, pluriparentais, anaparental, simultâneas etc.). Nesse contexto, pensar em um conceito que abarque a pluralidade de fatores que envolve a família pode se demonstrar uma tarefa árdua.

Entretanto, a problematização do conceito e a sinalização em documentos oficiais sobre o aspecto plural presente no termo se apresentam como possibilidade inicial para o desenvolver de uma discussão ou procura de um conceito que abarque as possíveis configurações familiares. Afinal, quando estamos abordando políticas públicas em saúde, como a PNAB, procuramos desenvolver políticas de caráter universal que não sejam excludentes, ou seja, "políticas públicas dirigidas à família devem dirigir-se a todas as famílias". ${ }^{11: 355}$ Os conceitos utilizados na construção da política pública sofrem processos de redefinição e produção de significados sociais, amplificam e propagam possíveis ideais e formas de percepções socioculturais, o que pode gerar alterações importantes no tecido social. ${ }^{27}$ Por isso, são necessários uma atenção e cuidado com a propagação de ideais que podem gerar processos de exclusão ou de não definição, como é no caso do termo família.

No final, a resposta para a pergunta "de que família estamos falando?" no contexto da PNAB não existe, pois a política não aborda sobre qual família ela versa. Ela aborda e descreve a importância de uma família no processo saúde e doença, mas não assume a sua descrição, deixando um campo a ser explorado sobre as crenças e práticas que surgem na indefinição que a política produz. 


\section{CONSIDERAÇÕES FINAIS E IMPLICAÇÕES PARA A PRÁTICA}

Um dos termos centrais na lógica de funcionamento do SUS, a família foi alocada com peça-chave no repensar do paradigma saúde/doença no Brasil, sendo celebrada como diferencial no cuidado em saúde. A centralidade atribuída ao termo reverbera em diversos modos, seja no desenvolvimento de estratégias à elaboração de campanhas, a família se torna alvo de ações que prezam pela saúde da população. Diretrizes são desenvolvidas para orientar o cuidado envolvendo esse termo, guiando os profissionais de saúde para a melhor aplicação das atividades descritas. Todavia, a partir da discussão elaborada alhures, existe uma pendência na utilização do termo família na saúde no que concerne à reflexão teórica.

Existe uma organização de informações na práxis que envolve a família no campo da saúde que lotam as várias edições da PNAB, mas o mesmo não ocorre na reflexão sobre a importância e polissemia do termo família, apesar de abordar a importância do termo nas ações da APS. Como demonstrado no resgaste histórico da família no Brasil, o termo passa por diversas transformações que alteram as configurações, funções e papéis sociais estabelecidos no seio familiar, havendo um caráter temporal/mutável que possibilita a pluralidade de interpretações e sinaliza para um cuidado acerca da aplicação do termo.

A falta de algum elemento que sinalize, ou uma definição, ou uma discussão sobre a pluralidade do termo, pode contribuir para uma divergência entre as ideais propostos pela PNAB e a práxis dos profissionais. Torna-se critério subjetivo do profissional sobre o seu entendimento de família, o que pode acarretar diferentes vieses e questionamentos éticos para a prática no dia a dia da atuação. Isso ocorre principalmente quando a compreensão individual que o profissional possui sobre o termo família diverge da realidade que emerge no cotidiano, o que pode possibilitar ações de negligências no cuidado de famílias que divergem de configurações hegemônicas e na perpetuação de estigmas e discriminação sobre as relações.

Mesmo diante das limitações do estudo teórico-reflexivo, que se embasam nas percepções e experiências - teóricas e práticas - singulares dos autores, na tentativa de contribuir para essa discussão, podemos pensar em possíveis opções sobre como manejar a problemática apresentada no campo da saúde. Primeiro, trazer à discussão (ou, ao menos, sinalizar) para os textos oficiais a pluralidade do termo família e a importância do seu reconhecimento para o paradigma saúde/doença, apontando as possíveis formas que esse termo possa assumir. Segundo, desenvolver estudos sobre as diferentes crenças e práticas que podem surgir no campo da família, no âmbito da saúde, tanto na concepção teórica quanto na prática. Terceiro, capacitar, por meio de uma educação permanente em saúde, os profissionais que abordam esse tema em seu dia a dia.

Essas possibilidades não abarcam a totalidade de formas que podem auxiliar na discussão do termo família, sendo ainda necessárias outras contribuições para esse campo. Contudo, elas podem minimizar as dificuldades e conflitos que surgem no fazer dos profissionais, ao se deparar com a pluralidade da realidade familiar e, ao mesmo tempo, aplicar os preceitos estabelecidos pelo modelo da Reforma Sanitária, no compreender dos vários aspectos que influência os indivíduos em seu processo de saúde/doença.

\section{AGRADECIMENTOS}

À Fundação Cearense de Apoio ao Desenvolvimento Científico e Tecnológico (FUNCAP), pela bolsa de mestrado concedida a um dos autores. Processo n BMD-0008-01323.01.17/19.

\section{CONTRIBUIÇÕES DOS AUTORES}

Concepção do desenho de reflexão. Lucas Lima Campos. Anna Karynne Melo.

Levantamento do referencial teórico para a condução da reflexão. Lucas Lima Campos. Anna Karynne Melo.

Análise do referencial teórico. Lucas Lima Campos. Anna Karynne Melo.

Interpretação do referencial teórico. Lucas Lima Campos. Anna Karynne Melo.

Redação e revisão crítica do manuscrito. Lucas Lima Campos. Anna Karynne Melo.

Aprovação da versão final. Lucas Lima Campos. Anna Karynne Melo.

Responsabilidade por todos os aspectos do conteúdo e a integridade do artigo publicado. Lucas Lima Campos. Anna Karynne Melo.

\section{EDITOR ASSOCIADO}

Maria Catarina Motta (B)

\section{EDITOR CIENTÍFICO}

Marcelle Miranda da Silva (iD

\section{REFERÊNCIAS}

1. Rocha SMC. A família como um direito humano atravessando tempos e histórias. Missões Rev Ciências Humanas e Sociais. 2019;4(1):1-7.

2. Silva GL. A família no processo de cuidar. Rev Ciência e Desenvolv [Internet]. 2019; [citado 2021 dez 17]; 12(2):369-85. Available from: http:// srv02.fainor.com.br/revista/index.php/memorias/arti cle/view/905/475

3. Stamp $\mathrm{GH}$. Theories of family relationships and a family relationships theoretical model. In: Vangelisti AL, editor. Handbook of family communication. 1st ed. New Jersey: Lawrence Erlbaum Associates 2003. p. 793.

4. Stamp GH, Shue CK. Twenty years of family research published in communication journals: a review of the perspectives, theories,concepts, and contexts. In: Vangelisti AL, editor. The Routledge Handbook of Family Communication. 2nd ed. New York: Routledge; 2012.

5. Serapioni M. O papel da família e das redes primárias na reestruturação das políticas sociais. Cien Saude Colet. 2005 dez;10(suppl.):243-53. http://dx.doi.org/10.1590/S1413-81232005000500025.

6. Tavares IL, Banaco RA, Borsa JC. O que é família para você? Opinião de crianças sobre o conceito de família. Av en Psicol Latinoam. 2020 jul;38(2):1-15. http://dx.doi.org/10.12804/revistas.urosario.edu.co/ apl/a.7178. 
7. Fragoso GL. Quando uma imagem não diz tudo: análise do discurso da logomarca da Estratégia Saúde da Família à luz do conceito de família contemporânea. Cien Saude Colet. 2020 nov;25(11):4293301. http://dx.doi.org/10.1590/1413-812320202511.04032019. PMid:33175038.

8. Archanjo DR. Família e saúde: uma abordagem histórica. In: Archanjo DR, Archanjo LR, Silva LL, editors. Saúde da Família na atenção primária. 1. ed. Curitiba: Intersaberes; 2013. p. 23-48.

9. Trad LAB. A família e suas mutações: subsídios ao campo da saúde. In: Trad LAB, editor. Família contemporânea e saúde: significados, práticas e políticas públicas. Rio de Janeiro: Fiocruz; 2010. p. 27-50 http://dx.doi.org/10.7476/9788575413227.

10. Mioto RCT. A família como referência nas políticas públicas:dilemas e tendências. In:Trad LAB, editor. Família contemporânea e saúde: significados, práticas e políticas públicas. 1. ed. Rio de Janeiro: Fiocruz; 2010.

11. Vargas MLF. Aportes das ciências sociais e humanas sobre família e parentesco: contribuições para a Estratégia Saúde da Família. Hist Cienc Saude Manguinhos. 2021 jun;28(2):351-74. http://dx.doi.org/10.1590/ s0104-59702021000200002. PMid:34190784.

12. Ferlini VLA. Sugar and the formation of colonial Brazil. In: Oxford University Press, editor. Oxford research encyclopedia of Latin American History. Oxford: Oxford research encyclopedia of Latin American History; 2019. http://dx.doi.org/10.1093/acrefore/9780199366439.013.729.

13. Vainfas R. Gender and Sexuality in Colonial Brazil. In: Oxford University Press, editor. Oxford research encyclopedia of Latin American History Oxford: Oxford research encyclopedia of Latin American History; 2021. http://dx.doi.org/10.1093/acrefore/9780199366439.013.280.

14. Cunha MF. Casamentos mistos: Entre a escravidão e a liberdade FrancaSão Paulo/Brasil, Século XIX. Rev Bras Estud Popul. 2017;34(2):223-42. http://dx.doi.org/10.20947/S0102-3098a0022.

15. Moreira VML. Casamentos indígenas, casamentos mistos e política na América portuguesa: amizade, negociação, capitulação e assimilação social. Topoi [Internet]. 2018 set; [citado 2021 dez 17]; 19(39):29-52. Available from: http://www.scielo.br/scielo.php?script=sci arttext\&pid=S223 7- .

16. Silva LS OC. As dotadas e meeiras da Capitania da Paraíba. Luso-Braz Rev [Internet]. 2020 jun; [citado $2021 \mathrm{dez}$ 17];57(1):30-57. Available from: http://lbr.uwpress.org/lookup/doi/10.3368/lbr.57.1.E14.
17. Marques NS, Temer MC, Seixas FF, Mendes AA, Alves LMN. A evolução do conceito de família brasileira. II Seminário Científico da FACIG; 2016 nov. 17-18; Manhuaçu. Manhuaçu: UNIFACIG; 2019; $p$. 57-66.

18. Rezende $\mathrm{CB}$. Famílias contemporâneas: reflexões sobre estratégias de sobrevivência. Serviço Soc e Real. 2012;21(2):47-64.

19. Fraiz IC. Saúde e Sociedade. In: Archanjo DR, Archanjo LR, Silva LL, editores. Saúde da Família na atenção primária. 1. ed. Curitiba: Intersaberes; 2013. p. 49-74.

20. Pinto LF, Giovanella L. The family health strategy: expanding access and reducing hospitalizations due to ambulatory care sensitive conditions (ACSC). Cien Saude Colet. 2018;23(6):1903-14. http:// dx.doi.org/10.1590/1413-81232018236.05592018. PMid:29972498.

21. Moraes PM, Nunes R, Horst CHM, Mioto RCT. Familismo e política social: aproximações com as bases da formação sócio-histórica brasileira. Rev Políticas Públicas. 2020 dez;24(2):802. http://dx.doi. org/10.18764/2178-2865.v24n2p802-818.

22. Oliveira AC. Famílias, cuidados e políticas públicas no Brasil contemporâneo Acervo. 2017;30(1):195-208

23. Gomes CBS, Gutiérrez AC, Soranz D. Política Nacional de Atenção Básica de 2017: análise da composição das equipes e cobertura nacional da Saúde da Família. Cien Saude Colet. 2020 abr;25(4):132738. http://dx.doi.org/10.1590/1413-81232020254.31512019. PMid:32267435.

24. Morosini MVGC, Fonseca AF, Lima LD. Política Nacional de Atenção Básica 2017: retrocessos e riscos para o Sistema Único de Saúde. Saúde Debate. 2018 jan;42(116):11-24. http://dx.doi.org/10.1590/01031104201811601

25. Sarti C. O lugar da família no programa de saúde da família. In: Trad LAB, editor. Família contemporânea e saúde: significados, práticas e políticas públicas. Rio de Janeiro: Fiocruz; 2010. p. 91-104.

26. Queiroz TA, Carvalho FPB, Simpson CA, Barreto ÉLF, Fernandes ACL. Família: significado para os profissionais da estratégia de saúde da família. Rev Bras Promoç Saúde. 2015 Jun;28(2):274-80. http://dx.doi. org/10.5020/18061230.2015.p274

27. Fleury S, Ouverney AM. Política de saúde: uma política social. In: Giovanella L, Escorel S, Lobato LVC, Noronha JC, Carvalho Al, editores. Políticas e sistema de saúde no Brasil. 3. ed. Rio de Janeiro: Editora Fiocruz; 2012. p. 1-42.

\footnotetext{
a A população indígena e africana (no Brasil colônia) sofreu influência da lógica europeia, mas não houve a total perda de certas características, como a poligamia, praticada por povos indígenas (que influenciou também os europeus). Entretanto, com o passar do tempo, essas populações foram obrigadas a seguirem a noção de família estabelecida pelo governo e pela igreja católica, que colocava o casamento (monogâmico) para toda a sociedade, minimizando as relações impuras. A população africana, na condição de escravo, tinha a possibilidade de formar família dentro das condições estabelecidas pelos seus senhores (que possuía a garantia dos direitos sobre qualquer criança nascida da união dos escravos). ${ }^{14,15}$

${ }^{\mathrm{b}}$ Ao utilizar o termo processos históricos, estamos nos referindo a mudanças especificas no contexto familiar e fatos que acometem a sociedade como um todo (e.g., mudanças nos papeis de gênero e sexualidade, eventos econômicos, políticos etc.).
} 